\title{
Acute cannabis consumption and motor vehicle collision risk: systematic review of observational studies and meta-analysis
}

\author{
(c) (1) (8) OPEN ACCESS
}

\author{
Mark Asbridge associate professor, Jill A Hayden assistant professor, Jennifer L Cartwright research \\ coordinator
}

Department of Community Health and Epidemiology, Dalhousie University, Halifax, Nova Scotia, Canada B3H 1V7

\begin{abstract}
Objective To determine whether the acute consumption of cannabis (cannabinoids) by drivers increases the risk of a motor vehicle collision. Design Systematic review of observational studies, with meta-analysis. Data sources We did electronic searches in 19 databases, unrestricted by year or language of publication. We also did manual searches of reference lists, conducted a search for unpublished studies, and reviewed the personal libraries of the research team.
\end{abstract}

Review methods We included observational epidemiology studies of motor vehicle collisions with an appropriate control group, and selected studies that measured recent cannabis use in drivers by toxicological analysis of whole blood or self report. We excluded experimental or simulator studies. Two independent reviewers assessed risk of bias in each selected study, with consensus, using the Newcastle-Ottawa scale. Risk estimates were combined using random effects models.

Results We selected nine studies in the review and meta-analysis. Driving under the influence of cannabis was associated with a significantly increased risk of motor vehicle collisions compared with unimpaired driving (odds ratio 1.92 (95\% confidence interval 1.35 to 2.73); $P=0.0003$ ); we noted heterogeneity among the individual study effects $\left(l^{2}=81\right)$. Collision risk estimates were higher in case-control studies (2.79 (1.23 to 6.33); $P=0.01)$ and studies of fatal collisions (2.10 (1.31 to 3.36$) ; P=0.002)$ than in culpability studies (1.65 (1.11 to 2.46$) ; P=0.07$ ) and studies of non-fatal collisions (1.74 (0.88 to 3.46); $\mathrm{P}=0.11$ ).

Conclusions Acute cannabis consumption is associated with an increased risk of a motor vehicle crash, especially for fatal collisions. This information could be used as the basis for campaigns against drug impaired driving, developing regional or national policies to control acute drug use while driving, and raising public awareness.

\section{Introduction}

Despite being regulated in many jurisdictions, cannabis (marijuana) is the most widely used illicit substance in the world. Results from the 2009 Canadian Alcohol and Drug Use Survey have indicated that $11.4 \%$ of Canadians overall and $33 \%$ of those aged 15-24 years used cannabis at least once in the previous year. ${ }^{1}$ Rates of driving under the influence of cannabis have also risen in recent years; national data collected in 2004 indicate that $4 \%$ of Canadian adults reported driving within one hour of consuming cannabis, up from $1.9 \%$ recorded in 1996-7. ${ }^{2}$ These results are reflected in other jurisdictions across the world. A roadside survey of 537 drivers in Scotland reported that $15 \%$ of respondents aged 17-39 years admitted to having consumed cannabis within 12 hours of driving a vehicle, ${ }^{3}$ and the European Monitoring Centre for Drugs and Drug Addiction found that between $0.3 \%$ and $7.4 \%$ of drivers tested positive for cannabis from roadside surveys in the United Kingdom, Denmark, the Netherlands, Norway, the United States, and Australia. ${ }^{4}$

Much of the early research assessing the effects of cannabis on driving performance was done by laboratory and driving simulator studies. The results of these studies are generally consistent: at increased doses, cannabis impairs the psychomotor skills necessary for safe driving. ${ }^{5-12}$ However, although laboratory studies have high internal validity with regard to the dose related effects of cannabis on performance, the dose-response association is unclear in relation to driving ability and collision risk outside the laboratory. ${ }^{7813}{ }^{14}$ As a result, these studies do not always translate well to driving scenarios in the real world, and generally focus on experienced cannabis users consuming the drug in unorthodox surroundings and undertaking tasks that do not always reflect the complex nature of driving in natural settings. ${ }^{15}$

Observational epidemiology studies can assess driving in the general population and are able to address many of the limitations of laboratory studies. ${ }^{16}$ Three types of epidemiological studies are commonly used to investigate cannabis use and motor vehicle collisions: cross sectional studies, cohort studies, and case-control studies. Many cross sectional studies have reported on cannabis incidence in injured or fatally injured drivers, as well as in the general driving public. ${ }^{17-23}$ In these studies, cannabis is consistently one of the 
most frequently detected psychoactive substances (second after alcohol), and individuals who drive within two hours of using cannabis have raised rates of collision. ${ }^{24}$

Fewer case-control and cohort studies have looked at cannabis consumption and collision risk, and their results have been inconsistent. ${ }^{55-27}$ More than half of these studies have suggested that cannabis consumption is associated with an increased risk of traffic collision, ${ }^{21}{ }^{23}$ and the remaining studies have found no association or a decreased risk of collision. ${ }^{29-33}$ Researchers have also used a variant of case-control designs, often known as culpability studies. ${ }^{34}$ Culpability studies include drivers involved in collisions, separated into those who were responsible for the collision and those who were not. The premise of these studies is that, if cannabis use increases collision risk, the drug should more likely be detected in drivers judged to be responsible for their collision. However, culpability analyses have also produced mixed results. ${ }^{35-39}$

Therefore, a lack of consensus exists on whether the risk of motor vehicle collisions is elevated or lowered when drivers have recently consumed cannabis. Furthermore, very few robust studies on this subject are generalisable to situations in the real world. An up to date systematic review is necessary to integrate the existing evidence on the role of cannabis use on collision risk, not only from a public policy and programme perspective, but also in view of the current gaps in scope and quality of literature and methodology.

We did a systematic review of the observational epidemiology literature to ascertain whether the acute consumption of cannabis or cannabinoids by drivers increases the risk of a motor vehicle collision, and to explore the impact of potential biases due to outcome measurement and confounding on the observed effect sizes.

\section{Methods}

We used a systematic review approach similar to that advocated by the Cochrane Collaboration, ${ }^{8}$ appropriately modified for the epidemiological nature of our review objective and available data. We included a comprehensive search, transparent study selection and data extraction, risk of bias assessment, and synthesis of sufficiently similar data. We selected observational studies with a control or comparison group, including cohort (historical prospective), case-control, and culpability designs. We excluded experimental laboratory or simulator studies. We included studies if they assessed acute or recent cannabis use by the toxicological analysis of whole blood or via self report, with participants drawn from hospital studies, roadside studies, studies of collisions (including fatal collision) drawn from police records, and self report studies.

We included studies that assessed motor vehicle collisions, defined by the World Health Organization as "a collision or incident that may or may not lead to injury, occurring on a public road and involving at least one moving vehicle." ${ }^{40}$ Motor vehicles included cars, vans, sport utility vehicles, light or heavy trucks, buses, motorcycles or scooters, all terrain vehicles, and snowmobiles. Collision outcomes included single or multiple vehicles, which might have led to injuries or death, and could be measured via administrative data or self report. We did separate assessments of the impact of cannabis consumption on fatal or non-fatal outcomes and on case-control or culpability studies.

\section{Literature search and selection}

The search strategy included several data sources and was not restricted by language of publication or by year. We did electronic searches in the following databases, with the help of an experienced library scientist: the Cochrane Library (including the Cochrane Central Register of Controlled Trials (CENTRAL), Cochrane Database of Systematic Reviews (CDSR), Database of Abstracts of Reviews of Effects (DARE), Health Technology Assessment (HTA) Database, NHS Economic Evaluation Database (EED)), Medline, Embase, PsycInfo, Cumulative Index to Nursing and Allied Health Literature, SocIndex, Sociological Abstracts, Web of Science, Academic Search Premier, ProQuest Library, Alcohol Studies Database, the Alcohol and Alcohol Problems Database, LegalTrac,

Transportation Research Information Service (TRIS) database Online, and OSHLINE.

Searches were conducted between 13 August and 2 September 2010. We used the following search terms, and adapted these for each database if appropriate:

- ((“Accidents, Traffic"[MeSH]) OR ("Motor Vehicles”[MeSH])) OR (accident* OR crash* OR collision* OR collide*) AND

- (car OR automobile* OR vehicle* OR traffic* OR road OR “off-road") AND

- ((“Cannabis”[MeSH] OR “Cannabinoids”[MeSH]) OR "Marijuana Smoking”[MeSH]) OR

(“Tetrahydrocannabinol”[MeSH]) OR (hemp OR cannabis OR Marihuana OR marijuana OR pot OR hashish OR Ganja OR thc OR Tetrahydrocannabinol)).

In addition to the electronic search, we browsed reference lists of included studies and related reviews identified in the electronic search, and reviewed the personal libraries of the research team. We included published reports investigating the association between cannabis use and motor vehicle collision. Two reviewers (MA and JLC) independently screened the search results and identified studies that were potentially relevant. They reviewed studies in three stages, based on each paper's title, abstract, and full text. The reviewers reached consensus at each stage of the screening process.

\section{Data collection}

For selected studies, two reviewers (MA and JLC) extracted data separately using pretested data extraction forms. They discussed any discrepancies in data extraction and sought the assessment of a third reviewer (JAH) for resolution. Extracted information included relevant study details (authors, year, geographical area, study design, sample size), population characteristics (mean age, male sex, setting), exposure (method and timing), bivariate and multivariate associations between exposure and outcome, and the incidence of outcomes from motor vehicle collisions for each study population and for the unexposed group (to allow comparisons across populations and outcome measures).

\section{Quality assessment for individual studies}

Two reviewers (MA and JLC) assessed the quality of each selected study using the Newcastle-Ottawa scale. ${ }^{41}$ This scale awards a maximum of nine stars to each study: four stars for the adequate selection of cases and controls, two stars for comparability of cases and controls on the basis of the design and analysis, and three stars for the adequate ascertainment of the exposure in both the case and control groups. We defined studies of high quality as those that scored the maximum nine 
stars on the Newcastle-Ottawa scale; studies of medium quality scored seven or eight stars. One discrepancy in quality assessment was discussed and resolved by the two reviewers.

\section{Synthesis of results}

Study estimates of the effect of cannabis on collision risk are often confounded by the failure to separate out the effects of alcohol and other psychoactive substances. Therefore, our analyses focused on tetrahydrocannabinol, the main psychoactive component of cannabis. We searched for any positive test for active metabolites of tetrahydrocannabinol, and assessed the presence of tetrahydrocannabinol alone, in the absence of alcohol or other drugs. Our primary analysis focused on measures that best captured recent use: consumption measured by the presence of active tetrahydrocannabinol metabolites or 11-hydroxy-delta-9-tetrahydrocannabinol in blood.

Odds ratios were extracted from each study, or were calculated by the reviewers (MA and JLC) if the odds ratio of interest was not explicitly stated. In the event of missing information, study authors were contacted by email. In addition to our primary analysis, we used subgroup analyses to explore the effects of study design, quality, and outcome on estimates of risk. Meta-analyses used random effects modelling and Mantel-Haenszel estimates in Review Manager 5.1 (Cochrane Collaboration, Oxford, UK). We rated the overall quality of our evidence by considering the internal validity, generalisability, heterogeneity, and precision of included studies, following recommendations by the Grading of Recommendations Assessment, Development and Evaluation Working Group.

\section{Results}

\section{Study selection}

Our literature search found 2975 studies; we selected 222 for abstract review, and brought forward 23 for full text review. We identified another 16 studies from reference searching. One paper from the reference search was selected for inclusion, together with nine from the full text search (fig $1 \Downarrow$ ).

We excluded studies after full text review that analysed the presence of inactive metabolites of tetrahydrocannabinol, or those with urine and blood test results that could not be separated. Although three of the included studies did test for the presence of cannabinoids in urine, we included data only if the presence of the active metabolite was also confirmed by a blood sample. ${ }^{23}{ }^{39} 42$ After data extraction, we excluded another study because it contained duplicated data from a previous paper (fig 1).

\section{Characteristics of included studies}

The meta-analysis included observational studies of motor vehicle drivers who had been treated for serious injuries sustained in a crash or had been involved in a fatal crash (table $\Downarrow$ ). ${ }^{23} 3942434445464748$ All studies tested for

tetrahydrocannabinol by analysing blood samples or using direct self reports of cannabis use in the three hours before the crash, and all analyses included the active form of

tetrahydrocannabinol. Studies were a mixture of case-control and culpability designs, were undertaken in different countries, and used various data sources such as medical records, roadside testing stations, administrative data (that is, the Fatal Accident Reporting System), and coroners' reports. Rates of cannabis use for cases ranged from $2 \%$ to $15 \%$, with rates for controls ranging from less than $1 \%$ to $7 \%$.

\section{Risk of bias assessment}

Four studies were deemed to be of high quality and five of medium quality; no studies were rated as low quality. Of the medium quality studies, one reported large differences in response rates for cases and controls, but lacked objective confirmation of self reported marijuana use. ${ }^{44}$ Another study showed a potential bias in participant selection because it used data only from drivers aged 20-49 years. ${ }^{43}$ The remaining three studies were not clear about which factors were controlled for in their analyses of results. ${ }^{42} 43$

Across studies, the main bias related to exposure measurement was the concurrent use of alcohol or other drugs in addition to cannabis. Although data were available for alcohol, insufficient information was available to account for the effect of other illicit drugs. Since this bias would overestimate the effect of cannabis on collision risk, we calculated odds ratios using "cannabis only" cases and controls - that is, only those motorists whose system contained cannabis without any other drugs or alcohol present.

Seven of the nine included studies found that the risk of a motor vehicle collision increased when drivers had consumed cannabis within a few hours before the crash, ${ }^{39} 424344454647$ with two studies concluding that the risk of a collision while under the influence of cannabis was less than the risk for unimpaired drivers. ${ }^{23} 48$ The positive association between cannabis use and motor vehicle collision risk ranged from 1.36 (95\% confidence interval 0.59 to 3.15$)^{42}$ to $7.16(2.77 \text { to } 18.52)^{44}$ (fig $2 \Downarrow$ ). Most studies used $1 \mathrm{ng} / \mathrm{ml}$ of cannabis or any amount greater than zero as the cutoff for a positive test result, 23394345464748 with one study using a $2 \mathrm{ng} / \mathrm{ml}$ cutoff $^{42}$ and another using only self report. $^{44}$

\section{Primary and secondary analyses}

Our primary analysis looked at the risk of a motor vehicle collision while under the influence of cannabis and included all nine studies (relating to 49411 participants). The pooled risk of a motor vehicle collision while driving under the influence of cannabis was almost twice the risk while driving unimpaired (odds ratio 1.92 (95\% confidence interval 1.35 to 2.73 ); $\mathrm{P}=0.0003$ ); we noted heterogeneity among the individual study effects $\left(I^{2}=81 \%\right)$.

We also assessed culpability and non-culpability studies separately and explored differences between motor vehicle collisions resulting in deaths and non-fatal injuries.

Meta-analyses on subgroups of studies explored the potential effect of specific features related to study design and potential biases: case-control studies versus culpability studies, fatal collisions versus non-fatal collisions, and high quality studies versus medium quality studies (fig $3 \Downarrow$ ).

High quality studies had a pooled odds ratio that was higher than that for medium quality studies, although both results showed a significant association at the 0.05 level. Furthermore, case-control studies (2.79 (1.23 to 6.33); $\mathrm{P}=0.01$ ) estimated the effect of cannabis use on crash risk to be higher than that estimated by culpability studies (1.65 (1.11 to 2.46$) ; \mathrm{P}=0.07)$. Studies of fatal collisions (2.10 (1.31 to 3.36); $\mathrm{P}=0.002)$ had a pooled odds ratio that was statistically significant, but studies of non-fatal collisions (1.74 ( 0.88 to 3.46$) ; \mathrm{P}=0.11$ ) did not show significant results.

In all studies assessing cannabis use in conjunction with alcohol, the estimated odds ratio for cannabis and alcohol combined was higher than for cannabis use alone, suggesting the presence of a synergistic effect. ${ }^{21} 233537$ 


\section{Overall quality of evidence}

The overall quality of the evidence on the association between cannabis use and motor vehicle collisions was moderate. Most studies in our meta-analysis consistently showed an increased effect of cannabis use on the risk of motor vehicle collisions. All studies were graded seven points or above on the nine point Newcastle-Ottawa scale for quality. The studies were heterogeneous (as shown in our primary analysis), and we used random effects models for the meta-analyses. Confidence intervals for most of the subgroup analyses were narrow. Overall, we regarded our results to be generalisable to cannabis related crashes resulting in serious injuries or death, in which alcohol and other drugs are not confounding factors.

\section{Publication bias}

Figure $4 \Downarrow$ shows a funnel plot examining possible publication bias. These results should be interpreted with caution, because our meta-analysis included only nine studies, and current guidelines do not recommend testing for funnel plot asymmetry in analyses of fewer than 10 studies. ${ }^{49}$ Nevertheless, we did not see evidence of important small study bias or publication bias.

\section{Discussion}

After a systematic review of the literature, this meta-analysis of studies examining acute cannabis consumption and motor vehicle collisions, with adequate control groups, found a near doubling of risk of a driver being involved in a motor vehicle collision resulting in serious injury or death. The increased risk was most evident for high quality studies, case-control studies, and studies of fatal collisions. The impact of acute cannabis consumption on the risk of minor crashes remains unclear. To our knowledge, this meta-analysis is the first to examine the association between acute cannabis use and the risk of motor vehicle collisions in real life settings. This review is important to enhance our understanding of the effects of cannabis consumption on collision risk, and provides a more definitive statement on the direction that efforts in public policy and intervention should take in addressing road safety.

These results converge with those from experimental studies (laboratory, simulator, and forensic) suggesting that cannabis impairs performance of the cognitive and motor tasks necessary for safe driving, increasing the risk of collision. ${ }^{10}{ }^{11}$ The results also accord with recent data for collisions that point to the increasing presence of drugs other than alcohol (especially cannabis and depressants of the central nervous system) in injured and fatally injured drivers. ${ }^{50}{ }^{51}$ Surveys of young drivers have also shown that rates of driving under the influence of cannabis have surpassed rates of drinking and driving in some jurisdictions. ${ }^{24}{ }^{52}$ Nevertheless, alcohol remains the substance most often present in crashes, and the observed association between cannabis consumption and crash risk is less robust than that for alcohol.${ }^{53}$ For example, a blood alcohol concentration of $0.8 \mathrm{~g} / 100 \mathrm{~mL}(17.36 \mathrm{mmol} / \mathrm{l})$, which is the criminal threshold for impairment in many jurisdictions, is associated with an increased relative risk of a crash of 2.69 , with a substantially higher risk for drivers aged 35 years and younger. ${ }^{54} 55$

Studies included in the meta-analysis showed considerable heterogeneity of the effect of cannabis use. ${ }^{49}$ Differences in risk estimates between culpability and case-control studies might have been partly due to the nature of the non-culpable group that acts as a control group in culpability studies. By definition, people in this group are not true controls, because they have been involved in a motor vehicle collision but have been found not at fault for the crash. Therefore, baseline crash risk in non-culpable drivers is biased upwards, with smaller effect sizes than would be found in a crash free control, and might mitigate the effect of tetrahydrocannabinol on crash risk in culpability studies. Differences in the nature of the control groups between study designs could account for the more conservative effect estimated from the culpability studies, as well as from the studies of medium quality.

We observed that cannabis had an increased influence on the risk of motor vehicle collision for studies of fatally injured drivers, which might be explained by the differences in tetrahydrocannabinol concentrations. Although we did not examine dose effects on the risk and severity of collisions, studies of fatally injured drivers found higher amounts of tetrahydrocannabinol in the blood (either by heavier consumption of cannabis or owing to the shorter time period between consumption and measurement) than those observed in studies of non-fatal injuries. ${ }^{5056}$ For fatally injured drivers, tetrahydrocannabinol is measured at a time equivalent to death, as opposed to non-fatal crashes in which the compound is assessed many hours after the crash. Furthermore, drivers in non-fatal crashes are more likely to refuse drug testing, increasing the measurement bias.

Simulator studies have also found a substantial dose-response effect, in which raised concentrations of tetrahydrocannabinol were associated with increased crash risk. Only three of the reviewed studies included calculations of odds ratios at differing tetrahydrocannabinol concentrations; in all three studies, raised amounts of the substance increased the risk of crash. ${ }^{23} 3945$ Since only one of the included studies assessed infrequent or habitual use of cannabis by drivers, we were unable to distinguish between tetrahydrocannabinol amounts in occasional and habitual cannabis users. ${ }^{44}$

\section{Limitations}

Legal thresholds for driver impairment due to cannabis consumption are inconsistent; the judgment of impairment varies in different regions, from observed impairment via sobriety test results only to measured tetrahydrocannabinol amounts in the blood or serum of 7-10 ng/ml. ${ }^{56}$ Furthermore, such thresholds are less meaningful in view of evidence indicating that cannabis impairment can be at its peak despite low measurements of tetrahydrocannabinol in the blood. ${ }^{58}$ Furthermore, the presence of cannabis at the time of a collision is calculated differently across studies (on the basis of serum, whole blood, or self report), and could include subjective measures of acute consumption or recent use. Several jurisdictions have attempted to legislate cannabis use by drivers by using a zero tolerance policy ${ }^{50}$ our review lends weight to their assumption that recent cannabis use increases motor vehicle collision risk. However, the studies in our review did not have enough data on tetrahydrocannabinol concentration to examine dose-response effects. Therefore, our data cannot assess legislation based on legal thresholds of cannabis impairment.

We found considerable heterogeneity across the studies in our review $\left(\mathrm{I}^{2}=81 \%\right)$. We used a random effects model after postulating a priori that our populations would be heterogeneous, because of varying data sources and the differing methods used to measure tetrahydrocannabinol concentrations. Although we defined high quality studies as those that scored full marks on the Newcastle-Ottawa scale, many of these high and medium quality studies probably did not control for all possible confounders. Although we restricted positive cannabis results to drivers that showed the presence of tetrahydrocannabinol in the absence of other drugs or alcohol, other potentially important 
confounders were probably not controlled for. These hidden confounders, as well as the differing study designs used, might have affected the results of the individual studies and hence the estimates of the pooled odds ratios.

Using our inclusion criteria, we selected only studies of serious injuries and deaths resulting from motor vehicle collisions. Cannabis might also be a risk factor for minor collisions, although the association between cannabis consumption and collisions was significant for fatal motor vehicle collisions, and not significant for non-fatal crashes. Tetrahydrocannabinol concentrations might also be important, with minor collisions more likely than fatal collisions to involve drivers with lower concentrations of cannabis. Future reviews could assess minor collisions with control groups drawn from the general driving population.

Contributors: MA and JAH designed data collection tools, monitored data collection, and drafted and revised the paper. MA and JLC assessed articles for inclusion in the review and for risk of bias and study quality, with JAH as consulting author in case of disagreements. JLC collected and analysed the data, and revised the paper. The review was carried out with the assistance of two decision makers; the Nova Scotia Road Safety Advisory Committee and the Canadian Centre on Substance Abuse. All authors had full access to all of the data in the study and take responsibility for the integrity of the data and the accuracy of the data analysis.

Funding: This review was funded by the Canadian Institutes of Health Research. The funding source had no role in study design; in the collection, analysis, and interpretation of data; in the writing of the report; or in the decision to submit this article for publication. All researchers worked independently of the funding agency.

Competing interests: All authors have completed the Unified Competing Interest form at www.icmje.org/coi_disclosure.pdf (available on request from the corresponding author) and declare: all authors had financial support from Dalhousie University and the Canadian Institutes of Health Research for the submitted work; no financial relationships with any organisations that might have an interest in the submitted work in the previous 3 years; no other relationships or activities that could appear to have influenced the submitted work.

Ethics approval: Not required.

Data sharing: Search strategies and results, as well as details of excluded studies at each stage of the search are available on request from the corresponding author.

1 Health Canada. Canadian alcohol and drug use survey: summary of results for 2008.2008 www.hc-sc.gc.ca/hc-ps/drugs-drogues/stat/_2008/summary-sommaire-eng.php.

2 Centre for Addiction and Mental Health. Cannabis use and driving among Ontario adults. 2003. www.camh.net/Research/Areas_of research/Population_Life Course Studies/ eBulletins/eb020 cannabisdriving.pdf.

3 Neale J, McKeganey N, Hay G, Oliver J. Recreational drug use and driving: a qualitative study. Scottish Executive Central Research Unit, 2000.

4 European Monitoring Centre for Drugs and Drug Addiction. Drug use, impaired driving and traffic accidents. Insights no 8 . Office for Official Publications of the European Communities, 2008 .

5 Bates MN, Blakely TA. Role of cannabis in motor vehicle crashes. Epidemiol Rev 1999:21:222-32.

6 Moskowitz H. Marijuana and driving. Accident Anal Prev 1995;17:323-45.

7 Ashton C. Pharmacology of cannabis: a brief review. Br J Psychiatry 2001;178:101-6.

8 O'Kane CJ, Tutt DC, Bauer LA. Cannabis and driving: a new perspective. Emerg Med 2002;14:296-303.

$9 \quad$ Iversen L. Cannabis and the brain. Brain 2003:126:1252-70.

10 Ramaekers JG, Berghaus G, van Laar M, Drummer OH. Dose-related risk of motor vehicle crashes after cannabis use. Drug Alcohol Depend 2004;73:109-19.

11 Berghaus G, Guo BL. Medicines and driver fitness-findings from a meta-analysis of experimental studies as basic information to patients, physicians, and experts. In: Koedan CN, McLean AJ, eds. Alcohol, Drugs, and Traffic Safety-T'95: Proceedings for the 13th International Conference on Alcohol, Drugs, and Traffic Safety. University of Adelaide, 1995:295-300

12 Berghaus G, Friedel B, International Council on Alcohol, Drugs and Traffic Safety Working Group. Guidelines on experimental studies undertaken to determine a medicinal drug's effect on driving or skills related to driving. International Council on Alcohol, Drugs and Traffic Safety, 1999.

13 Heishman S, Arasteh K, Stitzer M. Comparative effects of alcohol and marijuana on mood, memory and performance. Pharmacol Biochem Behav 1997;58:93-101.
14 Greenwald M, Stitzer M. Antinociceptive, subjective and behavioral effects of smoked marijuana in humans. Drug Alcohol Depend 2000:59:261-75.

15 Robbe HWJ, O'Hanlon JF. Marijuana and actual driving performance. Final report DOT HS 808078. US Department of Transportation, National Highway Traffic Safety Administration, 1993.

16 Tallories Report. Guidelines for drugged driving research. International Council on Alcohol, Drugs and Traffic Safety, 2007.

17 Cimbura G, Lucas DM, Bennett RC, Donelson AC. Incidence and toxicological aspects of cannabis and ethanol detected in 1394 fatally injured drivers and pedestrians in Ontario (1982-1984). J Forensic Sci 1990;35:1035-41.

18 Stoduto G, Vingilis E, Kapur BM, Sheu WJ, McLellan BA, Liban CB. Alcohol and drug use among motor vehicle collision victims admitted to a regional trauma unit: demographic, injury, and crash characteristics. Accid Anal Prev 1993;25:411-20.

19 Mercer G, Jeffery W. Alcohol, drugs and impairment in fatal traffic accidents in British Columbia. Accid Anal Prev 1995;27:335-43.

20 Dussault C, Brault M, Bouchard J, Lemire AM. The contribution of alcohol and other drugs among fatally injured drivers in Quebec: some preliminary results. In: Mayhew DR, Dussault C, eds. Proceedings of the 16th International Conference on Alcohol, Drugs and Traffic Safety. Société de l'Assurance Automobile du Québec, 2002:423-30.

21 Mura P, Kintz P, Ludes B, Gaulier JM, Marquet P, Martin-Dupont S, et al. Comparison of the prevalence of alcohol, cannabis and other drugs between 900 injured drivers and 900 control subjects: results of a French collaborative study. Forensic Sci Int 2003;133:79-85.

22 Soderstrom C, Dischinger P, Kerns T, Trifillis AL. Marijuana and other drug use among automobile and motorcycle drivers treated at a trauma center. Accid Anal Prev 1995;27:131-5.

23 Laumon B, Gadegbeku B, Martin J-L, Biecheler M-B, SAM Group. Cannabis intoxication and fatal road crashes in France: population based case-control study. BMJ 2005;331:1371-7.

24 Asbridge M, Poulin C, Donato A. Driving under the influence of cannabis and motor vehicle collision risk: evidence from adolescents in Atlantic Canada. Accid Anal Prev 2005;37:1025-34

25 Robbe $\mathrm{H}$. Marijuana's impairing effects on driving are moderate when taken alone but severe when combined with alcohol. Hum Psychopharm 1998;13:S70-8.

26 Vingilis E, MacDonald S. Review: drugs and traffic collisions. Traffic Inj Prev 2002;3:1-11.

27 MacDonald S, Anglin-Bodrug K, Mann RE, Erickson P, Hathaway A, Chipman M, et al. Injury risk associated with cannabis and cocaine use. Drug Alcohol Depend 2003;72:99-115.

28 Blows S, Ivers RQ, Connor J, Ameratunga S, Woodward M, Norton R. Marijuana use and car crash injury. Addiction 2005;100:605-11.

29 Meulemans A, Hooft P, Van Camp L, De Vrieze N, Buylaert W, Verstraete A, et al. Belgian Toxicology and Trauma Study: une étude portante sur la présence d'alcool, de médicaments et de drogues illicites chez des conducteurs victimes d'accidents de la route. Toxicological Society of Belgium and Luxembourg, 1996.

30 Marquet P, Delpla P-A, Kerguelen S, Bremond J, Facy F, Garnier M, et al. Prevalence of drugs of abuse in urine of drivers involved in road accidents in France: a collaborative study. J Forensic Sci 1998;43:806-11.

31 Movig KL, Mathijssen MP, Nagel PH, van Egmond T, de Gier JJ, Leufkens HG, et al. Psychoactive substance use and the risk of motor vehicle accidents. Accident Anal Prev 2004;36:631-6.

32 Ramaekers J, Berghaus G, van Laar M, Drummer OH. Performance impairment and risk of motor vehicle crashes after cannabis use. Proceedings of the International Scientific Conference on Cannabis . Rodin Foundation, Ministry of Public Health of Belgium, 2002:69-87.

33 Waller P, Blow F, Maio R, Singer K, Hill EM, Schaefer N. Crash characteristics and injuries of victims impaired by alcohol versus illicit drugs. Accid Anal Prev 1997;29:817-27.

34 Terhune K. An evaluation of responsibility analysis for assessing alcohol and drug crash effects. Accid Anal Prev 1983:15:237-46.

35 Drummer $\mathrm{OH}$. A review of the contribution of drugs in drivers to road accidents. In: Inquiry into the effects of drugs (other than alcohol) on road safety in Victoria, incorporating collected papers. LV North, Government Printer, 1995:1-28.

36 Longo M, Hunter C, Lokan R, White JM, White MA. The prevalence of alcohol, cannabinoids, benzodiazepines and stimulants amongst injured drivers and their role in driver culpability. Part 1: The prevalence of drug use in drivers and characteristics of drug positive group. Accid Anal Prev 2000;32:613-22.

37 Longo M, Hunter CE, Lokan R, White JM, White MA. The prevalence of alcohol, cannabinoids, benzodiazepines and stimulants amongst injured drivers and their role in driver culpability. Part 2: the relationship between drug prevalence and drug concentration, and driver culpability. Accid Anal Prev 2000;32:623-32.

38 Soderstrom C, Dischinger PC, Kufera JA, Ho SM, Shepard A. Crash culpability relative to age and sex for injured drivers using alcohol, marijuana or cocaine. Annual Proceedings/Association for the Advancement of Automotive Medicine 2005;49:327-41.

39 Drummer OH, Gerostamoulos J, Batziris H, Chu M, Caplehorn J, Robertson MD, et al The involvement of drugs in drivers of motor vehicles killed in Australian road traffic crashes. Accid Anal Prev 2004;36:239-48.

40 Peden M, Scurfield R, Sleet D, Mohan D, Hyder AA, Jarawan E, et al, eds. World report on road traffic injury prevention. World Health Organization, 2004.

41 Wells GA, Shea B, O'Connell D, Peterson J, Welch V, Losos M, et al. The Newcastle-Ottawa Scale (NOS) for assessing the quality of nonrandomised studies in meta-analyses. www.ohri.ca/programs/clinical_epidemiology/oxford.asp.

42 Mathijssen R, Houwing S. The prevalence and relative risk of drink and drug driving in the Netherlands: a case-control study in the Tilburg police district. SWOV publication R-2005-9. 2nd ed. SWOV Institute for Road Safety Research, 2005.

43 Bedard M, Dubois S, Weaver B. The impact of cannabis on driving. Can J Public Health 2007;98:6-11

44 Blows S, Ivers RQ, Connor J, Ameratunga S, Woodward M, Norton R. Marijuana use and car crash injury. Addiction 2005:100;605-11.

45 Longo MC, Hunter CE, Lokan RJ, White JM, White MA. Role of alcohol, cannabinoids, benzodiazepines and stimulants in road crashes. Alcohol, Drugs and Traffic Safety-T2000: Proceedings of the 15th International Conference on Alcohol, Drugs and Traffic Safety; 2000 May 22-26. International Council for Alcohol, Drugs \& Traffic Safety, 2000:363-74.

46 Mura P, Kintz P, Ludes B, Gaulier JM, Marquet P, Martin-Dupont S, et al. Comparison of the prevalence of alcohol, cannabis and other drugs between 900 injured drivers and 900 control subjects: results of a French collaborative study. Forensic Sci Int 2003;133:79-85. 


\section{What is already known on this topic}

Little consensus exists in the scientific literature on how driving under the influence of cannabis affects the risk of a motor vehicle collision in naturalistic settings

\section{What this study adds}

Acute cannabis consumption nearly doubles the risk of a collision resulting in serious injury or death; this increase was most evident for studies of high quality, case-control studies, and studies of fatal collisions

The influence of cannabis use on the risk of minor collisions remains unclear

These data could help inform policy and interventions tackling road safety and raise public awareness of the collision risks when driving under the influence of cannabis

47 Terhune KW. The role of alcohol, marijuana and other drugs in the accidents of injured drivers. Volume 1: findings. DOT HS-806-199. US Department of Transportation, National Highway Traffic Safety Administration, 1982.

48 Terhune KW, Ippolito CA, Hendricks DL, Michalovic JG, Bogema SC, Santinga P, et al. The incidence and role of drugs in fatally injured drivers. DOT HS-808-065. US Department of Transportation, National Highway Traffic Safety Administration, 1992.

49 Higgins JPT, Green S, eds. Cochrane handbook for systematic reviews of interventions. Version 5.1.0. 2011. www.cochrane-handbook.org.

50 Mura P, Chatelain C, Dumestre V, Gaulier JM, Ghysel MH, Lacroix C, et al. Use of drugs of abuse in less than 30-year-old drivers killed in a road crash in France: a spectacular increase for cannabis, cocaine and amphetamines. Forensic Sci Int 2006;160:168-72.

51 Beasley E, Beirness D, Porath-Waller A. A comparison of drug- and alcohol-involved motor vehicle driver fatalities. Canadian Centre on Substance Abuse, 2011.

52 Adlaf EM, Mann RE, Paglia A. Drinking, cannabis use and driving among Ontario students. CMAJ 2003;168:565-6.

53 Hall W, Homel R. Reducing cannabis-impaired driving: is there sufficient evidence for drug testing of drivers? Addiction 2007;102:1918-9.

54 Blomberg RD, Peck RC, Moskowitz H, Burns M, Fiorentino D. The Long Beach/Fort Lauderdale relative risk study. J Safety Res 2009;40:285-92.

55 Zador PL, Krawchuk SA, Voas RB. Relative risk of fatal and crash involvement by BAC age and gender. DOT HS 809 050. US Department of Transportation, National Highway Traffic Safety Administration, 2000
56 Jones AW, Holmgren A, Kugelberg FC. Driving under the influence of cannabis: a 10-year study of age and gender differences in the concentrations of tetrahydrocannabinol in blood. Addiction 2008;103:452-61.

57 Bramness JG, Khiabani HZ, Mørland J. Impairment due to cannabis and ethanol: clinical signs and additive effects. Addiction 2010;105:1080-7.

58 Harder S, Rietbrock S. Concentration-effect relationship of delta-9-tetrahydrocannabinol and prediction of psychotropic effects after smoking marijuana. Int Clin Pharmacol Ther 1997;35:155-9.

Accepted: 12 December 2011

\section{Cite this as: BMJ 2012:344:e536}

This is an open-access article distributed under the terms of the Creative Commons Attribution Non-commercial License, which permits use, distribution, and reproduction in any medium, provided the original work is properly cited, the use is non commercial and is otherwise in compliance with the license. See: http://creativecommons.org/licenses/by$\mathrm{nc} / 2.0 /$ and http://creativecommons.org/licenses/by-nc/2.0/legalcode. 


\section{Table}

Table 1/ Characteristics of the nine studies included in the meta-analysis

\begin{tabular}{|c|c|c|c|c|c|c|c|c|c|}
\hline Authors & Year & $\begin{array}{l}\text { Study } \\
\text { design }\end{array}$ & Outcome & $\begin{array}{l}\text { No of } \\
\text { participants } \\
\text { in sample* }\end{array}$ & Cases & Controls & Data setting & THC test procedure & Quality† \\
\hline Bedard et al & 2007 & Culpability & Deaths & 32543 & Culpable drivers & $\begin{array}{c}\text { Non-culpable } \\
\text { drivers }\end{array}$ & $\begin{array}{c}\text { Fatal Accident } \\
\text { Reporting System } \\
\text { database }\end{array}$ & $\begin{array}{l}\text { Testing of whole blood } \\
\text { by coroners }\end{array}$ & Medium \\
\hline Blows et al & 2005 & Case-control & Deaths & 1139 & $\begin{array}{l}\text { Drivers in } \\
\text { crashes }\end{array}$ & $\begin{array}{l}\text { Random sample of } \\
\text { drivers from } \\
\text { roadside }\end{array}$ & $\begin{array}{l}\text { Roadside testing, } \\
\text { medical and police } \\
\text { records }\end{array}$ & $\begin{array}{c}\text { Self report of acute } \\
\text { THC use in } 3 \text { hours } \\
\text { before crash }\end{array}$ & Medium \\
\hline $\begin{array}{l}\text { Drummer et } \\
\text { al }\end{array}$ & 2004 & Culpability & Deaths & 1590 & Culpable drivers & $\begin{array}{l}\text { Non-culpable } \\
\text { drivers }\end{array}$ & $\begin{array}{l}\text { Medical and police } \\
\text { records }\end{array}$ & $\begin{array}{l}\text { Testing of whole blood } \\
\text { by coroners }\end{array}$ & High \\
\hline Laumon et al & 2005 & Culpability & Deaths & 6765 & Culpable drivers & $\begin{array}{l}\text { Non-culpable } \\
\text { drivers }\end{array}$ & $\begin{array}{l}\text { Medical and police } \\
\text { records }\end{array}$ & GCMS on whole blood & High \\
\hline Longo et al & 2000 & Culpability & Injuries & 1975 & Culpable drivers & $\begin{array}{l}\text { Non-culpable } \\
\text { drivers }\end{array}$ & $\begin{array}{l}\text { Emergency } \\
\text { departments }\end{array}$ & $\begin{array}{c}\text { RIA followed by } \\
\text { GCMS on whole blood }\end{array}$ & Medium \\
\hline $\begin{array}{l}\text { Mathijssen et } \\
\text { al }\end{array}$ & 2005 & Case-control & Injuries & 3679 & Injured drivers & $\begin{array}{c}\text { Random sample of } \\
\text { drivers from } \\
\text { roadside }\end{array}$ & $\begin{array}{l}\text { Roadside testing, } \\
\text { medical and police } \\
\text { records }\end{array}$ & $\begin{array}{c}\text { Self report or } \\
\text { screening of serum, } \\
\text { confirmed by GCMS }\end{array}$ & Medium \\
\hline Mura et al & 2003 & Case-control & Injuries & 631 & $\begin{array}{c}\text { Drivers } \\
\text { attending the } \\
\text { emergency } \\
\text { department }\end{array}$ & $\begin{array}{c}\text { Other attendees of } \\
\text { emergency } \\
\text { department }\end{array}$ & $\begin{array}{l}\text { Emergency } \\
\text { departments }\end{array}$ & GCMS on whole blood & Medium \\
\hline Terhune & 1992 & Culpability & Deaths & 799 & Culpable drivers & $\begin{array}{l}\text { Non-culpable } \\
\text { drivers }\end{array}$ & $\begin{array}{l}\text { Medical and police } \\
\text { records, Fatal } \\
\text { Accident Reporting } \\
\text { System database }\end{array}$ & $\begin{array}{c}\text { RIA followed by } \\
\text { GCMS on whole blood }\end{array}$ & High \\
\hline Terhune & 1982 & Culpability & Injuries & 290 & Culpable drivers & $\begin{array}{l}\text { Non-culpable } \\
\text { drivers }\end{array}$ & $\begin{array}{l}\text { Emergency } \\
\text { departments }\end{array}$ & $\begin{array}{l}\text { Screening and testing } \\
\text { of blood plasma }\end{array}$ & High \\
\hline
\end{tabular}

THC=tetrahydrocannabinol; GCMS=gas chromatography and mass spectrometry; RIA=radioimmunoassay.

*Numbers represent the samples used in the present review and meta-analysis (THC only, no alcohol, or other drugs present), and do not represent the total numbers of participants in the original studies.

†Measurement based on the Newcastle-Ottawa scale. 


\section{Figures}

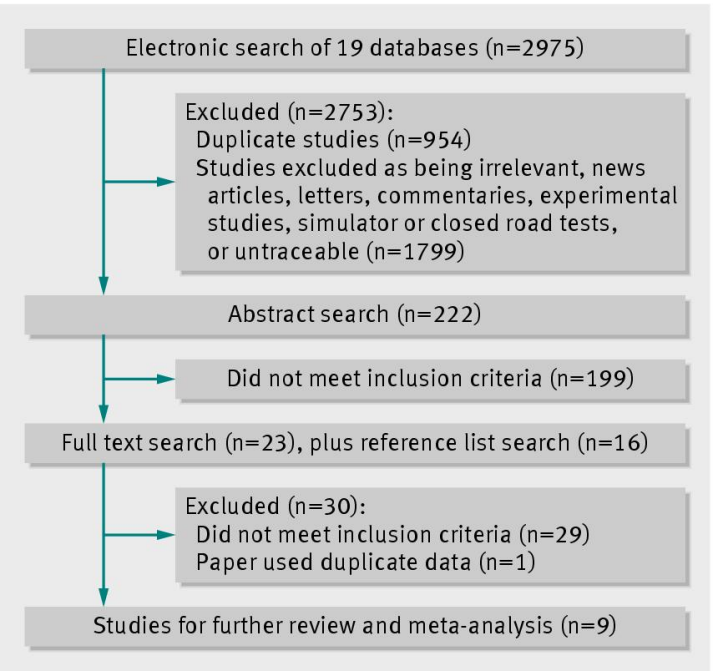

Fig 1 Study selection for systematic review

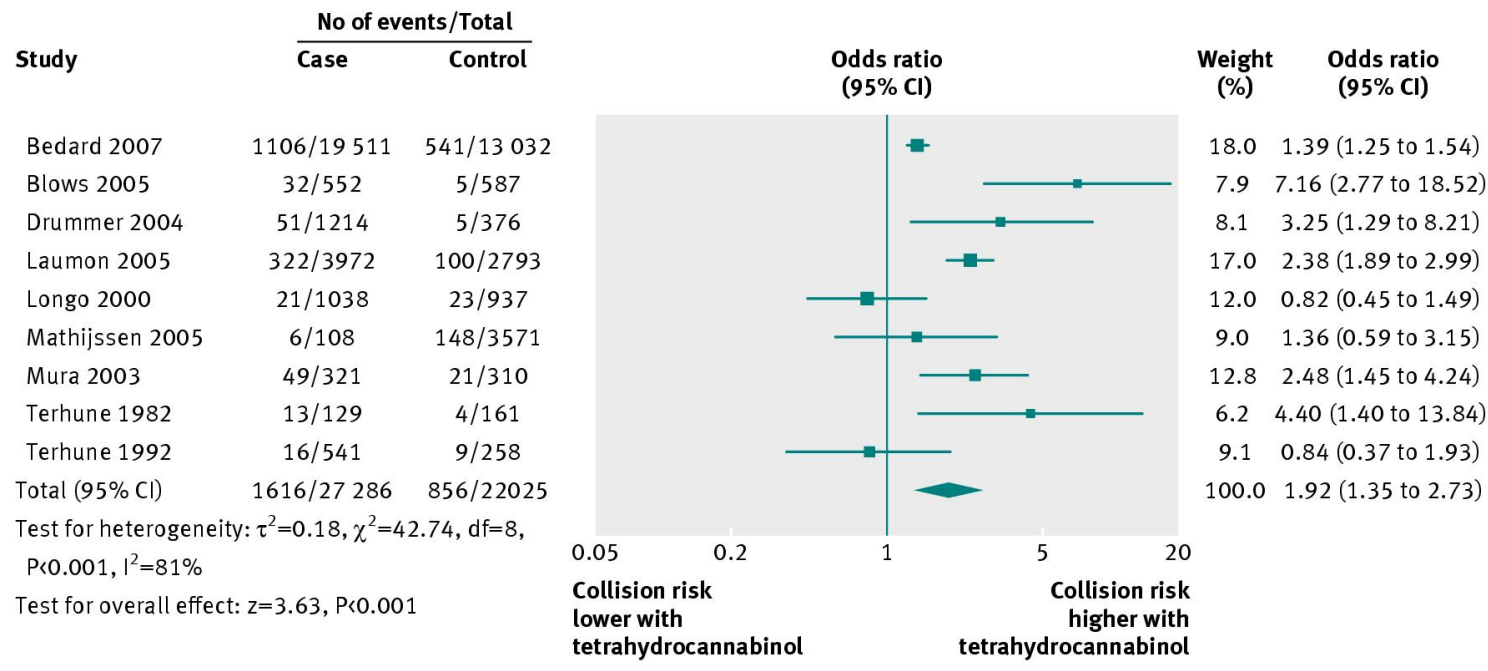

Fig 2 Meta-analysis of observational studies investigating the association between acute cannabis consumption and motor vehicle crashes

$\begin{array}{lccc}\text { Study } & \text { No } & \text { N } & \begin{array}{c}\mathbf{I}^{\mathbf{2}} \\ \mathbf{( \% )}\end{array} \\ \text { Case-control } & 3 & 5449 & 71 \\ \text { Culpability } & 6 & 43962 & 83 \\ \text { High quality } & 4 & 9444 & 60 \\ \text { Medium quality } & 5 & 39967 & 79 \\ \text { Fatal collisions } & 5 & 42836 & 88 \\ \text { Non-fatal collisions } & 4 & 6575 & 71\end{array}$
$1^{2}$
$(\%)$

1
83
6
9
8
1

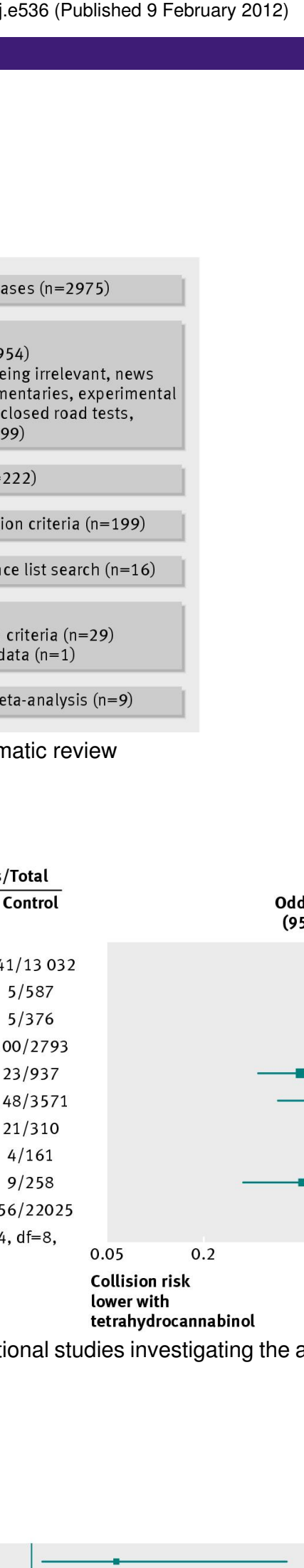

$(95 \% \mathrm{Cl})$

2.79 (1.23 to 6.33$)$

1.65 (1.11 to 2.46$)$

2.21 (1.25 to 3.90)

1.78 (1.07 to 2.94$)$

2.10 (1.31 to 3.36$)$

1.74 (0.88 to 3.46$)$

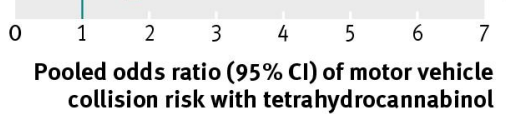

Fig 3 Pooled odds ratio $(95 \% \mathrm{Cl})$ of motor vehicle collision risk with tetrahydracannabinol for subgroups of studies 


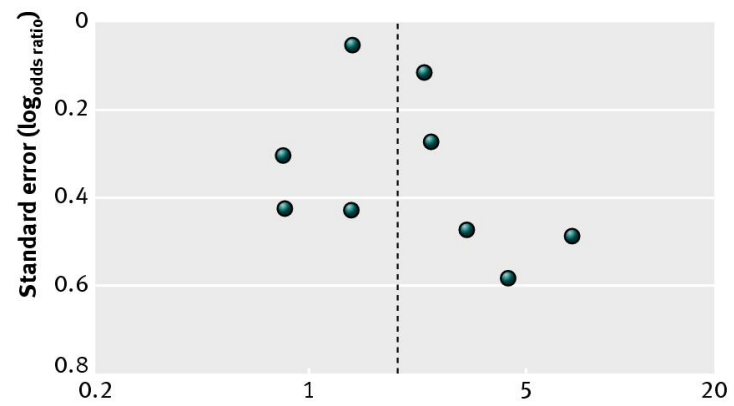

Odds ratio of motor vehicle collision risk with tetrahydrocannabinol

Fig 4 Funnel plot examining possible publication bias in studies investigating the association between acute cannabis consumption and risk of motor vehicle crashes. The horizontal axis measures the association (odds ratio) observed in individual studies, plotted against the standard error. The broken vertical line indicates our overall pooled estimate from meta-analysis (odds ratio 1.92) 